\title{
Prophylaxis and Incidence of Symptomatic Deep Vein Thrombosis in Indian Patients with Sepsis: DETECT-Deep Vein Thrombosis Registry
}

\author{
Nagarajan Ramakrishnan, DETECT-DVT Investigators* \\ Department of Critical Care Medicine, Apollo Hospitals, Chennai, Tamil Nadu, India
}

Abstract

Purpose: To assess thromboprophylaxis rate and incidence of symptomatic deep vein thrombosis (DVT) in Indian patients with acute sepsis. Materials and Methods: Adult patients with sepsis, within $48 \mathrm{~h}$ of sepsis onset/hospital admission were included. DVT was assessed using Doppler ultrasonography if clinical signs were present. Data were collected at inclusion, discharge, and $30 \pm 7$ days (if discharged before 30 days). Results: The study included 278 patients (men: 69.4\%; mean age: $56.3 \pm 17.99$ years). Out of 275 patients (data missing for 3 patients), 188 (68.4\%; 95\% confidence interval: 62.5-73.8) received DVT prophylaxis (185 at admission and 3 at discharge; pharmacological prophylaxis: $n=88$, mechanical prophylaxis: $n=65$, pharmacological + mechanical prophylaxis: $n=35)$ and 87 received no prophylaxis. In line with American College of Chest Physicians 2008 recommendations, among patients who received pharmacological prophylaxis $(n=123)$, low-molecular-weight heparin was given to $85.4 \%(n=105)$ patients (duration: $9.1 \pm 6.36$ days), unfractionated heparin to $12.2 \%(n=15)$ patients (duration: $9.2 \pm 9.18$ days), and fondaparinux to $5.7 \%(n=7)$ patients (duration: $6.8 \pm 3.30$ days); $27 / 63$ patients at high-risk of bleeding received mechanical prophylaxis; no patient received aspirin. Of 9 patients who developed DVT, 7 received no thromboprophylaxis (data missing for 2 patients). In total, 186/274 (67.9\%) patients recovered from sepsis. Conclusions: Two-third patients received thromboprophylaxis. The substantial role of thromboprophylaxis in DVT prevention mandates monitoring and control of thromboprophylaxis through internal audits in hospitals.

Keywords: Doppler ultrasonography, heparin (low molecular weight), Indian study (prospective), sepsis, venous thrombosis

\section{INTRODUCTION}

Sepsis, one of the oldest and most elusive syndromes, exhibits high mortality rates and is the most common cause of death among critically ill patients in noncoronary Intensive Care Units (ICUs). ${ }^{[1,2]}$ In a multicenter, prospective, observational study conducted in intensive therapy units in India, the incidence of severe sepsis was $13.1 \%$ of all admissions. ${ }^{[3]}$

Sepsis leads to complications in coagulation and may manifest from mild alterations to severe disseminated intravascular coagulation. ${ }^{[4]}$ In sepsis, toxins activate coagulation directly through the effect of chemical mediators on endothelium and monocytes. In addition, pro-inflammatory cascade can result in indirect coagulation. Sepsis-induced procoagulant activity is more severe than that produced by trauma. ${ }^{[5]}$ Severe sepsis predisposes patients toward venous thromboembolism (VTE) due to risk factors such as advanced age, chronic

\begin{tabular}{|l|l|}
\hline \multicolumn{3}{|c|}{ Access this article online } \\
\hline Quick Response Code: & Website: \\
\hline & www.ijccm.org \\
\hline
\end{tabular}

cardiopulmonary disease, recent surgery, immobilization, in-dwelling vascular catheters, and previous VTE history. Thromboembolic complications contribute to the burden of severe sepsis and are observed in approximately one out of every 32 severe sepsis patients. ${ }^{[6]}$

The international guidelines recommend deep vein thrombosis (DVT) prophylaxis with either twice or thrice daily low-dose unfractionated heparin (UFH) or daily low molecular weight heparin (LMWH) in patients with severe sepsis unless contraindicated (i.e., thrombocytopenia, severe coagulopathy,

Address for correspondence: Dr. Nagarajan Ramakrishnan, Department of Critical Care Medicine, Apollo Hospitals, 21 Greams Lane, Off Greams Road, Chennai - 600 006, Tamil Nadu, India. E-mail: ram@icuconsultants.com

This is an open access article distributed under the terms of the Creative Commons Attribution-NonCommercial-ShareAlike 3.0 License, which allows others to remix, tweak, and build upon the work non-commercially, as long as the author is credited and the new creations are licensed under the identical terms.

For reprints contact: reprints@medknow.com

How to cite this article: Ramakrishnan N. Prophylaxis and incidence of symptomatic deep vein thrombosis in Indian patients with sepsis: DETECT-deep vein thrombosis registry. Indian J Crit Care Med 2017;21:765-71. 
active bleeding, and recent intracerebral hemorrhage). Moreover, patients with a contraindication for heparin should receive mechanical prophylactic devices such as graduated compression stockings (GCS) or intermittent compression devices. Similarly, a combination of pharmacologic and mechanical therapy should be used in very high-risk severe sepsis patients with a history of DVT, trauma, or orthopedic surgery unless contraindicated or not practical. In addition, owing to proven superiority of LMWH in high-risk patients, it should be preferred over UFH. ${ }^{[7]}$ Subcutaneous heparin reduces the risk of thromboembolic events from $29 \%$ to $13 \%$ in ICU patients ${ }^{[8]}$ In a randomized prospective study, UFH significantly reduces mortality compared to no treatment ( $7.8 \%$ vs. $10.9 \%){ }^{[9]}$

The VTE prophylaxis is suboptimal in Asia due to a misconception that the incidence of VTE is lower in Asians than Caucasians; however, several studies have negated this belief. ${ }^{[10-12]} \mathrm{A}$ dearth of well-designed multicenter trials and discrepancies in the reported incidences have resulted in an underestimation of DVT incidence in the Indian population. ${ }^{[10,11]}$ The Asian VTE guidelines recommend a formal hospital VTE protocol for risk assessment and prophylaxis to dispel myths and institute a clear clinical pathway for the clinicians and hospital staff. ${ }^{[10]}$ Periodic studies assessing DVT incidence and thromboprophylaxis rates in India are essential for the development of strategies to improve the management of thromboprophylaxis.

The primary objective of this study was to determine the proportion of patients with sepsis who were given thromboprophylaxis. The secondary objectives were to determine the proportion of patients with sepsis developing DVT at discharge and to compare how many of these patients had received DVT prophylaxis, to evaluate the profile of patients admitted with sepsis, to determine the treatment for sepsis employed by the investigator in relation to thromboprophylaxis and antibiotic use, the outcome of sepsis, and DVT prophylaxis rate according to American College of Chest Physicians (ACCP) guidelines.

\section{Materials and Methods}

This was a prospective observational study conducted in accordance with the guidelines for Good Epidemiology Practice. Each participating site had taken all necessary permissions to conduct this study.

\section{Inclusion and exclusion criteria}

Adult inpatients with sepsis (including patients with severe sepsis and septic shock), from whom signed informed consent was obtained before initiation of the study (day of inclusion was considered to be within $48 \mathrm{~h}$ of onset of sepsis or within $48 \mathrm{~h}$ of current admission), were included. Patients who had participated in any clinical trial in the past 1 month were excluded.

\section{Definitions}

According to the International Guidelines for Management of Severe Sepsis and Septic Shock, 2012, sepsis was defined as the systemic response to infection, manifested by two or more of the following conditions as a result of infection:

1. Temperature $>38^{\circ} \mathrm{C}$ or $<36^{\circ} \mathrm{C}$

2. Heart rate $>90$ beats $/ \mathrm{min}$

3. Respiratory rate $>20$ breaths/min or partial pressure of carbon dioxide in arterial blood ( $\mathrm{PaCO}),<32 \mathrm{mmHg}$; and white blood cell count $>12,000 \mathrm{cmm}$ or $<4000 / \mathrm{cu} \mathrm{mm}$, or $>10 \%$ immature (band) forms. ${ }^{[13]}$

Severe sepsis referred to sepsis associated with organ dysfunction, hypoperfusion, or hypotension. Hypoperfusion and perfusion abnormalities included but were not limited to lactic acidosis, oliguria, or an acute alteration in mental status. ${ }^{[13]}$

Septic shock in adults referred to a state of acute circulatory failure characterized by persistent arterial hypotension unexplained by other causes. ${ }^{[14]}$

\section{Data collection}

At baseline (visit 1), patients satisfying the eligibility criteria were enrolled; their profile and the treatment modalities for sepsis along with DVT prophylaxis were recorded. Patients were assessed for the presence of DVT symptoms such as pain, swelling, and redness of the leg and dilatation of the surface veins at visit 1(baseline visit) and visit 2 (discharge)/ visit 3 ( $30 \pm 7$ days; if the patient was discharged after 30 days, data at visit 3 were not considered). Patients with these symptoms were evaluated for DVT using Doppler ultrasonography. Treatment modalities and the outcome of the sepsis were recorded. Data were transcribed from source documents (patient file, prescription letters, or any other relevant document) to case report forms.

\section{Statistical analysis}

Sample size: Assuming that $20 \%$ of the patients with sepsis would be given thromboprophylaxis, with a $90 \%$ confidence interval (CI) and 4\% precision, 269 patients were required for the study. Accounting for a drop-out of $20 \%, 340$ patients were required.

Descriptive statistics were done on patient characteristics and endpoints. Based on type of each variable (quantitative or qualitative), number of patients, means, standard deviations, percentages, and number of missing data were presented. Baseline characteristics were compared between patients with and without thromboprophylaxis, using Chi-square tests. $P<0.05$ was considered as significant. Statistical analysis was performed by Makrocare using SAS 9.1.3 (SAS Institute Inc., Cary, NC, USA).

\section{REsULTS}

\section{Patient disposition}

A total of 278 patients were recruited from 23 sites across India; 183 patients completed the study, while 91 patients discontinued the study for various reasons and data on study completion were missing for 4 patients. Of the 91 patients who did not complete 
study, one patient withdrew consent (only baseline data was analyzed for this patient), while the other 90 were included in the data analysis set of 278 patients. Death $(60.4 \%, 55 / 91)$ was the major cause of discontinuation, followed by discharge against medical advice $(30.8 \%, 28 / 91)$ [Figure 1].

\section{Demographics and clinical characteristics}

The mean age was $56.3 \pm 17.99$ years, and the majority $(n=193$, $69.4 \%$ ) were men. Among the 275 patients with sepsis, majority ( $n=127,46.2 \%)$ had sepsis that was not severe and was without septic shock, followed by severe sepsis $(n=94$, $34.2 \%)$ and septic shock $(n=54,19.6 \%)$. Majority of patients $(85.3 \%, 237 / 278)$ were admitted in corporate hospital with most patients $(59.4 \%, 165 / 278)$ in hospitals with $>301$ beds. The mean duration of hospital stay was $15.7 \pm 13.78$ days [Table 1].

\section{Proportion of patients receiving thromboprophylaxis}

Of the $68.4 \%(188 / 275 ; 95 \% \mathrm{CI}: 62.5-73.8)$ patients who received thromboprophylaxis, 65.4\% (123/188;

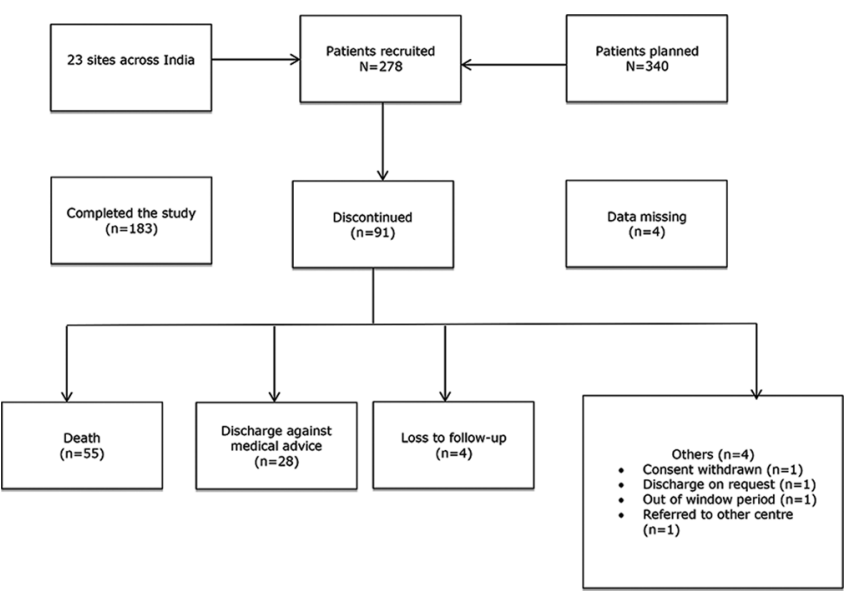

Figure 1: Patient disposition. n: Number of patients
95\% CI: 58.1-72.2) received pharmacological and 53.2\% (100/188; 95\% CI: 45.8-60.5) received mechanical thromboprophylaxis [Table 2]. About $46.8 \%$ patients $(88 / 188$; 95\% CI: 39.5-54.2) received pharmacological alone; $34.6 \%(65 / 188 ; 95 \% \mathrm{CI}: 27.8-41.8)$ received mechanical alone; 18.6\% (35/188; 95\% CI: 13.3-24.9) received both pharmacological and mechanical thromboprophylaxis. The main reason cited for not giving thromboprophylaxis was "Patient recovered" (pharmacological - 63.2\%, 96/152; mechanical - 57.1\%, 100/175) [Figure 2].

A high proportion of patients in the septic shock (74.1\%, 40/54), severe sepsis $(83.5 \%, 76 / 91)$, and sepsis that was not severe and without septic shock $(55.1 \%, 70 / 127)$ groups received thromboprophylaxis. Thromboprophylaxis was predominantly given to patients belonging to $\geq 61$ years age group $(79.2 \%, 95 / 120)$ in metro noncorporate hospitals $(78.6 \%, 11 / 14)$. Among patients receiving

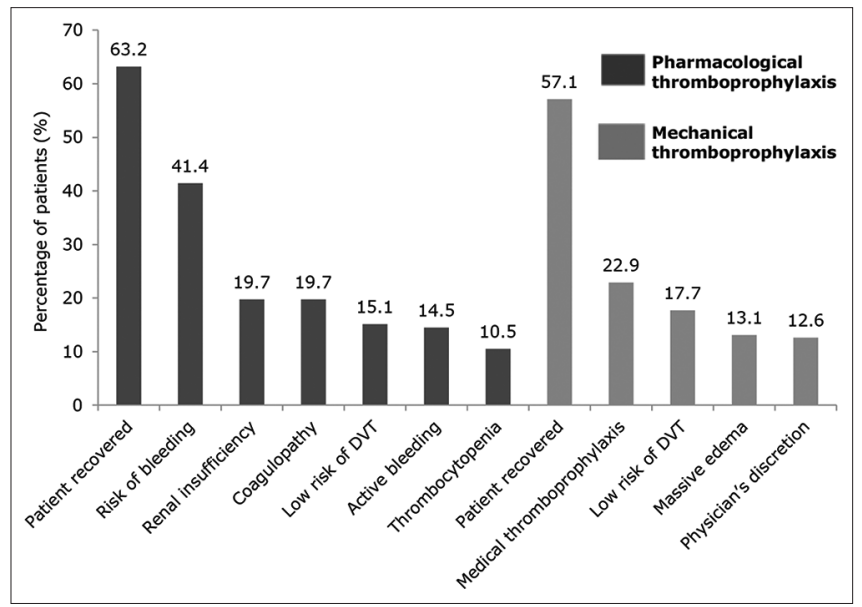

Figure 2: Major reasons for not administering pharmacological and mechanical thromboprophylaxis. DVT: Deep vein thrombosis

\begin{tabular}{|c|c|c|c|c|c|}
\hline Variable & $n(\%)$ & $\begin{array}{l}\text { Thromboprophylaxis } \\
\text { given }(n=188)\end{array}$ & $\begin{array}{l}\text { Thromboprophylaxis } \\
\text { not given }(n=87)\end{array}$ & Missing & $P$ \\
\hline \multicolumn{6}{|l|}{ Age (years) } \\
\hline$\leq 40$ & 54 & $31(57.4)$ & $23(42.6)$ & 1 & $0.0031^{\mathrm{a}}$ \\
\hline $41-60$ & 99 & $61(61.6)$ & $38(38.4)$ & 1 & - \\
\hline$\geq 61$ & 120 & $95(79.2)$ & $25(20.8)$ & 1 & - \\
\hline \multicolumn{6}{|l|}{ Gender } \\
\hline Male & 192 & $131(68.2)$ & $61(31.8)$ & 1 & $0.9419^{\mathrm{a}}$ \\
\hline Female & 83 & $57(68.7)$ & $26(31.3)$ & 2 & - \\
\hline \multicolumn{6}{|l|}{ Sepsis $(n=275)$} \\
\hline Severe sepsis & $91(34.2)$ & $76(83.5)$ & $15(16.5)$ & 3 & $<0.0001$ \\
\hline Septic shock & $54(19.6)$ & $40(74.1)$ & $14(25.9)$ & 0 & - \\
\hline Sepsis, not severe without septic shock & $127(46.2)$ & $70(55.1)$ & $57(44.9)$ & 0 & - \\
\hline \multicolumn{6}{|l|}{ Type of hospital } \\
\hline Rural hospital & $27(9.7)$ & $14(51.9)$ & $13(48.1)$ & 0 & 0.1189 \\
\hline Metro corporate hospital & $237(85.3)$ & $63(69.7)$ & $71(30.3)$ & 3 & - \\
\hline Metro noncorporate hospital & $14(5.0)$ & $11(78.6)$ & $3(21.4)$ & 0 & - \\
\hline
\end{tabular}

${ }^{a}$ Chi-square test was used to calculate the $P$ value. -: Not available 
thromboprophylaxis, $185 / 188$ patients received it at visit 1 (baseline) while $3 / 188$ patients received it at visit 2 (discharge). The baseline profile (in terms of age and stage of sepsis) was significantly different for patients who were given than those not given thromboprophylaxis [Table 1].

\section{Pharmacological thromboprophylaxis}

LMWH (85.4\%, 105/123; mean dose: $41.1 \mathrm{mg} /$ day; mean duration: $9.1 \pm 6.36$ days) was the most commonly used pharmacological prophylaxis followed by UFH (12.2\%, 15/123; mean dose: $9204.5 \mathrm{IU} /$ day; mean duration: $9.2 \pm 9.18$ days), fondaparinux $(5.7 \%, 7 / 123$; mean dose: $2.5 \mathrm{mg} /$ day; mean duration: $6.8 \pm 3.30$ days), and oral warfarin $(0.8 \%, 1 / 123$; mean dose: $7.5 \mathrm{mg}$ /day) [Table 2]. LMWH, UFH, and fondaparinux were administered subcutaneously.

\section{Mechanical thromboprophylaxis}

Intermittent pneumatic compression $(68.0 \%, 68 / 100)$ was the most common form of mechanical compression followed by GCS (29\%, 29/100) [Table 2].

\section{Proportion and clinical profile of patients who developed deep vein thrombosis}

In total, 9/278 (3.2\%) patients developed DVT; of them, 7 were not given thromboprophylaxis and data were missing for 2 patients. None of the patients receiving thromboprophylaxis developed DVT [Figure 3]. Of 9 patients who developed DVT, 6 were treated with LMWH alone, and 2 received LMWH and warfarin, and data were missing for 1 patient. Among the 9 patients with DVT, 4 were in the age group of 41-60 years, 6 were women, and 4 had severe sepsis at baseline; also, 5 patients were admitted in metro corporate hospitals while 4 in rural hospitals.

\section{Antibiotics used}

Major antibiotics and corresponding mean duration of use were piperacillin-tazobactam $(27.9 \%, 74 / 265 ; 8.3 \pm 5.52$ days $)$,

\begin{tabular}{lcc}
\hline \multicolumn{3}{l}{ Table 2: Type and duration of thromboprophylaxis $(\boldsymbol{n = 1 8 8 )}$} \\
\hline Category $^{\mathrm{a}}$ & $\boldsymbol{n}(\mathbf{\%})$ & $\begin{array}{c}\text { Duration of } \\
\text { treatment, days } \\
\text { (mean } \pm \text { SD) }\end{array}$ \\
\hline Pharmacological thromboprophylaxis & $123(65.4)$ & - \\
given & $105(85.4)$ & $9.1(6.36)$ \\
LMWH & $15(12.2)$ & $9.2(9.18)$ \\
UFH & $7(5.7)$ & $6.8(3.30)$ \\
Fondaparinux & $1(0.8)$ & - \\
Other & $1(0.8)$ & - \\
Oral warfarin & $100(53.2)$ & - \\
Mechanical thromboprophylaxis given & $29(29.0)$ & $11.2(6.68)$ \\
Graduated compression stockings & $68(68.0)$ & $13.1(13.40)$ \\
Intermittent pneumatic compression & $6(6.0)$ & - \\
Other & $1(1.0)$ & - \\
Deep vein thrombosis stockings & $5(5.0)$ & - \\
Thromboembolic deterrent stockings &
\end{tabular}

${ }^{a}$ Some patients were administered more than one type of mechanical thromboprophylaxis. -: Not available; SD: Standard deviation;

LMWH: Low-molecular-weight heparin; UFH: Unfractionated heparin meropenem $(26.8 \%, 71 / 265 ; 8.1 \pm 5.97$ days $)$, levofloxacin $(17.0 \%, 45 / 265 ; 7.5 \pm 3.77$ days $)$, metronidazole $(15.8 \%$, $42 / 265 ; 7.6 \pm 2.84$ days $)$, and cefoperazone-sulbactam $(13.6 \%$, $36 / 265 ; 6.5 \pm 4.38$ days).

\section{Outcome of sepsis}

At discharge, 186 (67.9\%) patients had recovered from sepsis, and $88(32.1 \%)$ did not recover from sepsis (data missing $=4$ ). Among patients who did not recover, 55/88 (62.5\%) died, $28 / 88(31.8 \%)$ were discharged against medical advice, $1 / 88(1.1 \%)$ was referred to some other center, $1(1.1 \%)$ was discharged on request, and data were missing for 3 patients.

Among 126 patients with nonsevere sepsis and who had no septic shock, $101(80.2 \%)$ had recovered and 25 (19.8\%) had not recovered. Similarly, out of 92 patients who had severe sepsis at baseline, 55 (59.8\%) had recovered and 37 (40.2\%) had not recovered. In 53 patients who had septic shock at baseline, 28 (52.8\%) had recovered and $25(47.2 \%)$ had not recovered.

\section{Evaluation of deep vein thrombosis prophylaxis according to American College of Chest Physicians guidelines}

1. For acutely ill patients with sepsis, ACCP recommends LMWH, UFH, or fondaparinux

- Pharmacological prophylaxis was given to $123 / 188$ patients $(65.4 \%)$. LMWH $(105 / 123,85.4 \%)$ was the most used pharmacological thromboprophylaxis followed by UFH (15/123, 12.2\%) and fondaparinux (7/123, 5.7\%).

2. ACCP recommends mechanical methods of thromboprophylaxis in patients at high risk of bleeding. Out of 63 patients with risk of bleeding, 27 (42.9\%) received mechanical thromboprophylaxis, $5(7.9 \%)$ received both pharmacological and mechanical thromboprophylaxis, and $36(57.1 \%)$ received neither pharmacological nor mechanical thromboprophylaxis

3. ACCP recommends against the use of aspirin alone as thromboprophylaxis for any patient group.

None of the patients received aspirin.

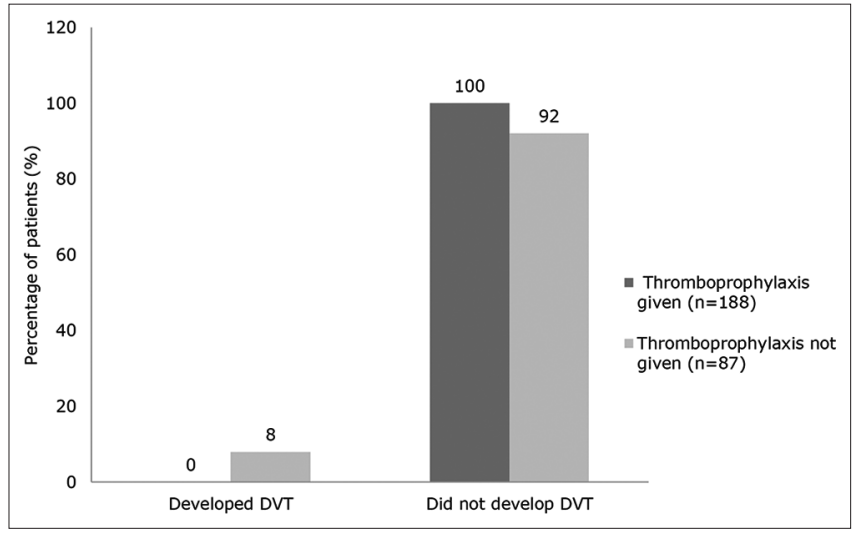

Figure 3: DVT development with respect to thromboprophylaxis administration. DVT: Deep vein thrombosis 


\section{Discussion}

This prospective observational study recruited 278 patients from 23 sites across India. Majority of the patients (46.2\%) had sepsis, which was not severe and without septic shock, followed by severe sepsis (34.2\%) and septic shock (19.6\%). Most patients (68.4\%) received thromboprophylaxis. None of the patients who received DVT prophylaxis developed DVT ( 9 patients developed DVT, out of which 7 patients were not given thromboprophylaxis and data on 2 patients were missing). Of 9 patients who developed DVT, 6 were treated with LMWH alone and 2 received LMWH and warfarin as DVT treatment. Most patients with sepsis at baseline recovered; highest proportion of patients recovered in the group where the stage of sepsis was not severe, and patients had no septic shock. The rate and method of DVT prophylaxis was largely in line with the ACCP guidelines, except for the large proportion of patients with high risk of bleeding $(57.1 \%, 36 / 63)$ who did not receive any prophylaxis.

\section{Proportion of patients given thromboprophylaxis}

The high risk for developing DVT seen in India makes it imperative to aggressively provide thromboprophylaxis unless contraindicated ${ }^{[15]}$ In CURVE (Multi-Centre Chart Audit of the Utilization of Risk Assessment and Prophylaxis of VTE in Acutely Ill Medical Patients in Canada), a national, multicenter thromboprophylaxis audit conducted in Canada, about $23 \%$ patients received thromboprophylaxis. ${ }^{[16]}$ In another prospective epidemiological observational study by ANZIC (Australian and New Zealand Intensive Care Society) center, a thromboprophylaxis rate of $86 \%$ was observed. ${ }^{[17]} \mathrm{A}$ review of the records of consecutive admissions to the medical ICU at Stanford and an affiliated Veterans Affairs hospital showed that $75 \%$ patients received thromboprophylaxis. ${ }^{[18]}$ A prospective observational study conducted in the ICU and wards in a tertiary care center in India showed a low DVT prophylaxis rate of $12.5 \% .^{[15]}$ In our study, $68.4 \%$ patients received thromboprophylaxis. These variations in the thromboprophylaxis rates could be due to different practices followed across varied clinical settings and differential level of compliance with international guidelines.

In this study, $65.4 \%$ patients received pharmacological thromboprophylaxis and $53.2 \%$ patients received mechanical thromboprophylaxis. A review of the records of all medical admissions to the ICUs of a university hospital in California showed about $20 \%$ patients receiving pharmacological prophylaxis, 38\% receiving mechanical prophylaxis, and $18 \%$ receiving prophylaxis by both methods. ${ }^{[18]}$ In an epidemiological audit of venous thromboprophylaxis management in critically ill patients including those with severe sepsis conducted by ANZIC center, $64 \%$ patients received pharmacological prophylaxis and $80 \%$ patients received mechanical prophylaxis. ${ }^{[17]}$ The differential proportion of patients receiving a particular type of thromboprophylaxis could be attributed to diversity in risk factors and their combinations observed in these patient groups. In this study,
"Patient recovered" was the main reason for not administering pharmacological and mechanical prophylaxis, which indicates that thromboprophylaxis is not being considered early in patients with sepsis. The American Society of Health-System Pharmacists suggests initiating thromboprophylaxis within $24 \mathrm{~h}$ of admission to the hospital. ${ }^{[19]}$ This highlights the suboptimal adherence to thromboprophylaxis guidelines and calls for their stricter implementation.

\section{Patients with deep vein thrombosis and association with thromboprophylaxis}

A historical cohort study examining all cases of DVT and pulmonary embolism during 1996-1997 at a large teaching hospital found that 1 in 6 cases of symptomatic VTE could be avoided with adequate administration of prophylaxis. ${ }^{[20]}$ This finding is corroborated by our study, where none of the patients who received thromboprophylaxis developed DVT. In an observational study done in a tertiary healthcare center in North India, Pandey et al. found a $25.8 \%$ prevalence of DVT (based on clinical signs and symptoms). ${ }^{[15]}$ However, in our study, 9 (3.2\%) patients developed symptomatic DVT. This difference could be due to major (85.3\%) recruitment from corporate hospitals (which might tend to have sepsis protocol for early detection and treatment in place), and thereby higher thromboprophylaxis rates in our study (68.4\%) compared to the earlier study (12.5\%).

\section{Outcome of sepsis}

In total, $186(67.9 \%)$ patients had recovered from sepsis at discharge; among those who did not recover, 55/88 (62.5\%) patients died. In a study involving 175,665 patients admitted to 134 ICUs in Australia and New Zealand, the omission of thromboprophylaxis within the first $24 \mathrm{~h}$ of ICU admission without obvious reasons resulted in an increased risk of mortality in critically ill adult patients which included sepsis patients. The association between the omission of early thromboprophylaxis and hospital mortality was particularly strong for patients with sepsis (OR, $1.52 ; 95 \% \mathrm{CI}, 1.27-1.81)$. $^{[21]}$ Further, a study of the records at medical ICU at Stanford and an affiliated Veterans Affairs hospital showed that the odds of death were $55 \%$ lower in patients receiving pharmacological prophylaxis compared with those receiving mechanical prophylaxis alone or no prophylaxis (odds ratio, $0.45 ; 95 \% \mathrm{CI}$ : $0.22-0.93 ; P=0.03) \cdot{ }^{[18]}$ Thus, the available evidence indicates that early and adequate initiation of thromboprophylaxis plays an important role in mortality rates in patients with sepsis.

\section{Evaluation of deep vein thrombosis prophylaxis according} to American College of Chest Physicians guidelines

For acutely ill medical patients admitted to hospital with sepsis, ACCP recommends thromboprophylaxis with LMWH, UFH, or fondaparinux. In our study, among those who received pharmacological thromboprophylaxis, $85.4 \%, 12.2 \%$, and $5.7 \%$ were given LMWH, UFH, and fondaparinux, respectively; whereas in other studies, more patients received UFH over LMWH (73\% vs. 24\%). ${ }^{[17,18]}$ The Surviving Sepsis Campaign recommends the use of LMWH daily for thromboprophylaxis 
instead of UFH twice daily, ${ }^{[22]}$ may be because hemorrhagic complications and pulmonary emboli incidences are shown to be less in patients who are administered with LMWH. ${ }^{[23-25]}$

Using mechanical prophylaxis reduces the risk of DVT by about two-thirds as monotherapy and by about half in combination with a pharmacological method. ${ }^{[26]}$ ACCP recommends mechanical thromboprophylaxis, primarily, in patients at high risk of bleeding. In this study, out of 63 patients with risk of bleeding, $42.9 \%$ received mechanical thromboprophylaxis, $7.9 \%$ received both pharmacological and mechanical thromboprophylaxis, and $57.1 \%$ did not receive any thromboprophylaxis. ACCP recommends against the use of aspirin alone as thromboprophylaxis for any patient group. Conforming to the ACCP guidelines, none of the patients received aspirin as thromboprophylaxis. The available evidence suggests that decisions regarding the type of prophylaxis should be based on risk factors for both thrombosis and bleeding, clinical context, and patients' values and preferences. ${ }^{[23]}$

\section{Strengths and limitations}

The study included patients from 23 sites across India (six from North, seven from South, three from East, and seven from West) and thus was representative of the diverse geographical population across the country. A prospective study design enabled collection of follow-up data on the outcome of sepsis. However, the study was subject to the shortcomings of observational studies such as confounding factors. The study centers included may have increased awareness about the use of VTE prophylaxis, thus impacting the rate of thromboprophylaxis. Furthermore, centers willing to participate may have different standards or practices than that of others. Patients were not evaluated for the presence of pulmonary embolism, which could be an important cause of death seen in this study. Only the presence of symptomatic DVT was assessed in patients with sepsis; further studies evaluating the prevalence of asymptomatic DVT in patients with sepsis would be required.

\section{Conclusions}

VTE represents one of the most crucial illnesses in patients with sepsis and is often overlooked and considered as an outcome of hospitalization, rather than a full-fledged disease entity. Given the substantial role of thromboprophylaxis in VTE prevention, internal audits in hospitals to monitor and control the process of thromboprophylaxis should be encouraged. The morbidity and mortality associated with VTE call for intensified efforts in identifying and addressing factors responsible for nonadherence to international guidelines and implementing strategies to promote compliance.

\section{Acknowledgment}

The authors acknowledge the assistance of Dr. Alina Gomes and Anahita Gouri with development of this manuscript, references, and figures and Dr. Ravi M. Tiwari from Sanofi for the conceptualization, coordination, and overall review of this study.

\section{Financial support and sponsorship}

This study was financially supported by Sanofi.

Dr. N. Ramakrishnan and other Detect DVT investigators were supported by unrestricted research grant for conducting the study.

\section{Conflicts of interest}

Nil.

\section{RefERENCES}

1. Angus DC, van der Poll T. Severe sepsis and septic shock. N Engl J Med 2013;369:840-51.

2. Mayr FB, Yende S, Angus DC. Epidemiology of severe sepsis. Virulence 2014;5:4-11.

3. Todi S, Chatterjee S, Bhattacharyya M. Epidemiology of severe sepsis in India. Crit Care 2007;11 Suppl 2:P65.

4. Saracco P, Vitale P, Scolfaro C, Pollio B, Pagliarino M, Timeus F, et al. The coagulopathy in sepsis: Significance and implications for treatment. Pediatr Rep 2011;3:e30.

5. Dellinger RP. Inflammation and coagulation: Implications for the septic patient. Clin Infect Dis 2003;36:1259-65.

6. Levi M, Levy M, Williams MD, Douglas I, Artigas A, Antonelli M, et al. Prophylactic heparin in patients with severe sepsis treated with drotrecogin alfa (activated). Am J Respir Crit Care Med 2007; 176:483-90.

7. Dellinger RP, Levy MM, Rhodes A, Annane D, Gerlach H, Opal SM, et al. Surviving sepsis campaign: International guidelines for management of severe sepsis and septic shock: 2012. Crit Care Med 2013;41:580-637.

8. Cade JF. High risk of the critically ill for venous thromboembolism. Crit Care Med 1982;10:448-50.

9. Halkin H, Goldberg J, Modan M, Modan B. Reduction of mortality in general medical in-patients by low-dose heparin prophylaxis. Ann Intern Med 1982;96:561-5.

10. Liew NC, Chang YH, Choi G, Chu PH, Gao X, Gibbs H, et al. Asian venous thromboembolism guidelines: Prevention of venous thromboembolism. Int Angiol 2012;31:501-16.

11. Cheng G, Chan C, Liu YT, Choy YF, Wong MM, Yeung PK, et al. Incidence of deep vein thrombosis in hospitalized Chinese medical patients and the impact of DVT prophylaxis. Thrombosis 2011;2011:629383.

12. Gandharba Ray MB. Venous thromboembolism- Indian perspective. Med Update 2010;20:329-34.

13. Surviving Sepsis Campaign: International Guidelines for Management of Severe Sepsis and Septic Shock; 2012. Available from: http://www guideline.gov/content.aspx?id=43904. [Last accessed on 2017 Feb 10].

14. Levy MM, Fink MP, Marshall JC, Abraham E, Angus D, Cook D, et al. $2001 \mathrm{SCCM} / \mathrm{ESICM} / \mathrm{ACCP} / \mathrm{ATS} / \mathrm{SIS}$ international sepsis definitions conference. Crit Care Med 2003;31:1250-6.

15. Pandey A, Patni N, Singh M, Guleria R. Assessment of risk and prophylaxis for deep vein thrombosis and pulmonary embolism in medically ill patients during their early days of hospital stay at a tertiary care center in a developing country. Vasc Health Risk Manag 2009;5:643-8

16. Kahn SR, Panju A, Geerts W, Pineo GF, Desjardins L, Turpie AG, et al. Multicenter evaluation of the use of venous thromboembolism prophylaxis in acutely ill medical patients in Canada. Thromb Res 2007;119:145-55.

17. Robertson MS, Nichol AD, Higgins AM, Bailey MJ, Presneill JJ, Cooper DJ, et al. Venous thromboembolism prophylaxis in the critically ill: A point prevalence survey of current practice in Australian and New Zealand Intensive Care Units. Crit Care Resusc 2010;12:9-15.

18. Lentine KL, Flavin KE, Gould MK. Variability in the use of thromboprophylaxis and outcomes in critically ill medical patients. Am J Med 2005;118:1373-80.

19. Mahan CE, Spyropoulos AC. ASHP therapeutic position statement on 
the role of pharmacotherapy in preventing venous thromboembolism in hospitalized patients. Am J Health Syst Pharm 2012;69:2174-90.

20. Arnold DM, Kahn SR, Shrier I. Missed opportunities for prevention of venous thromboembolism: An evaluation of the use of thromboprophylaxis guidelines. Chest 2001;120:1964-71.

21. Ho KM, Chavan S, Pilcher D. Omission of early thromboprophylaxis and mortality in critically ill patients: A multicenter registry study. Chest 2011;140:1436-46.

22. Lauzier F, Muscedere J, Deland E, Kutsogiannis DJ, Jacka M, Heels-Ansdell D, et al. Thromboprophylaxis patterns and determinants in critically ill patients: A multicenter audit. Crit Care 2014;18:R82.

23. Kahn SR, Lim W, Dunn AS, Cushman M, Dentali F, Akl EA, et al. Prevention of VTE in nonsurgical patients: Antithrombotic therapy and prevention of thrombosis, $9^{\text {th }}$ ed: American College of Chest
Physicians evidence-based clinical practice guidelines. Chest 2012;141:e195S-226S.

24. Robinson S, Toft $\mathrm{P}$. Thromboprophylaxis for intensive care patients. $\mathrm{Br}$ J Med Med Res 2014;4:46.

25. Rothberg MB, Pekow PS, Lahti M, Lindenauer PK. Comparative effectiveness of low-molecular-weight heparin versus unfractionated heparin for thromboembolism prophylaxis for medical patients. J Hosp Med 2012;7:457-63.

26. Roderick P, Ferris G, Wilson K, Halls H, Jackson D, Collins R, et al. Towards evidence-based guidelines for the prevention of venous thromboembolism: Systematic reviews of mechanical methods, oral anticoagulation, dextran and regional anaesthesia as thromboprophylaxis. Health Technol Assess 2005;9:iii-iv, ix-x, 1-78.

\section{AnNeXURe}

* Following is the list of the DETECT-DVT Investigators

Dr. Mohammed Faruk H. Memon, Ahmedabad;

Dr. Mayur Patel, Mumbai; Dr. Kedar Toraskar, Mumbai;

Dr. Leena Shah, Pune; Dr. Rajan Barokar, Nagpur;

Dr. Manish Jain, Mumbai; Dr. Sanjay Dhanuka, Indore;

Dr. V. K. Thakur, Bihar; Dr. Himjyoti Das, Meghalaya;

Dr. Animesh Gupta, Dr. Raymond Dominic Savio, Kochi;

Dr. V. N. Rajasekaran, Madurai; Dr. K. VijilRahulan,

Chennai; Dr. P. C. Vijaya Kumar; Chennai;

Dr. Ashwin K. Mani, Chennai; Dr. Chetan Goel, Mohali;

Dr. Amit Bery, Punjab; Dr. Naveen Gupta, Ludhiana;

Dr. Sandeep Diwan, New Delhi; Dr. Prakash Shastri,

New Delhi; Dr. Omender Singh, New Delhi;

Dr. Suhasini Tirumala, Secunderabad. 